\title{
A SEGUNDA HISTÓRIA DE RESPIRACIÓN ARTIFICIAL
}

\begin{abstract}
Livia Grotto é doutoranda em Teoria e História Literária na Universidade Estadual de Campinas. Atualmente, desenvolve a comparação, por meio do emblema do cristal, do primeiro livro de contos de Jorge Luis Borges, Historia universal de la infamia, e do conjunto de novelas curtas do escritor espanhol Ramón Gómez de la Serna, Doña Juana la loca, Superhistoria. Seu mestrado abordou a obra do escritor argentino Ricardo Piglia. Entre seus últimos artigos está "Entre Sur y Automoribundia: apuntes sobre la guerra civil", Hologramatica, año VI, n. 10, v. 3, 2009, pp. 93- 118.

E-mail: liviagrotto@gmail.com
\end{abstract}

Resumo: Respiração artificial do escritor Ricardo Piglia foi publicado em 1980, durante o processo militar instalado na Argentina entre 1976 e 1983. Este ensaio procura evidenciar como a mescla de vozes presente no romance denunciou as práticas da ditadura sem que a censura pudesse encontrar um culpado. Nesse sentido, privilegiam-se os sentidos que se situam na ordem do invisível, uma vez que não fazem parte direta da narrativa.
Resumée: Le roman Respiración artificial de l'écrivain Ricardo Piglia a été publié en 1980 dans la période de la dictature militaire qui s'est installé en Argentine dès 1976. Cet article cherche à montrer comment le mélange des voix dénonce les pratiques d'exception, sans que la censure eût pu réussir à trouver un coupable. Dans ce sens, on privilégie les sens qui sont de l'ordre de l'invisible, une fois qu'ils ne font pas partie de façon directe du récit.

Que tipo de homens são vocês? Isso mesmo, você também. Vocês inventam a teoria dos quanta e se deixam comandar por brutos que lhes dão um mundo a conquistar, mas que retiram de vocês o direito de escolher sua mulher. Respiração artificial e cada golpe acerta na mosca! Vocês são monstros ou capachos de monstros. Claro, eu não sou sensata, mas num mundo como este para que serve ter razão? Você está sentado aí e vê sua mulher arrumando as malas e não diz nada. As paredes têm ouvido, não é? Nada, vocês não dizem nada! Uns escutam, outros calam (Brecht, 1971, p. 67) ${ }^{1}$.

Nessa invectiva estão ensaiadas as últimas palavras de uma mulher contra seu marido, antes de a porta se abrir, na cena nove de Grande medo e miséria do III Reich, de Bertold Brecht. Esse quadro situa-se em Frankfurt, 1935. Antes dessa injúria, a personagem arrumava as malas e telefonava para uns e outros avisando que viajaria. A mulher não é nomeada. O cenário não é descrito. Ouve-se apenas a sua voz. Ela se despede primeiro de um amigo que costumava vir à sua casa jogar bridge. Pede a ele que entre em contato com seu marido logo que puder, talvez num domingo. Em seguida, liga para outra pessoa, quem sabe uma colega. Diz, delicadamente, que já não estaria lá, que ela e Max poderiam vir. Depois telefona à irmã de seu marido, pedindo que cuide dele. Chama, finalmente, uma amiga mais próxima, diz que tudo se tornou difícil demais, também para o marido. Desliga. Passa, então, a ensaiar a conversa que terá com o esposo. A cena intitula-se "A mulher judia".

Há uma enfermidade. A vida é mantida por meio de aparelhos: "respiração artificial", como assevera a mulher. Mesmo que o poder dos S.A. e S.S. e a ascensão de Hitler ao poder não estejam nomeados, eles se manifestam violentamente, invadindo e 
alterando as esferas da vida social e privada. Cada uma das outras vinte e quatro cenas são fragmentos que iluminam uma nova forma de pensar e agir, cujo ritmo crescente alastra-se pelo país, sem explicação e sem estupefação na maior parte dos casos. O cumprimento "Hei Hitler" atravessa a intimidade. Cada um vigia, desconfia e, em potencial, pode delatar familiares e amigos. Nesse ambiente, cada palavra pesa mais do que vale.

Respira-se artificialmente, dentro de uma atmosfera de medo e opressão. Todos se calam, porque não há outro modo: no momento em que a respiração falha, há silêncio, necessariamente. São cenário e asfixia similares aos tematizados por Ricardo Piglia em Respiración artificial, publicado em 1980, durante o processo militar instalado na Argentina entre 1976 e 1983. O título do romance, não explicitado em nenhuma parte, adere para, simultaneamente, inverter a versão do Estado fabricada, de acordo com o autor, como o seguinte "relato médico":

(...) el país estaba enfermo, un virus lo había corrompido, era necesario realizar una intervención drástica. El Estado militar se autodefinía como el único cirujano capaz de operar, sin postergaciones y sin demagogia. Para sobrevivir, la sociedad tenía que soportar esa cirugía mayor. Algunas zonas debían ser operadas sin anestesia (Piglia, 2000, pp. 113114).

A ditadura pode ser lida nas entrelinhas de Respiración artificial. Elas contam outra história, sobre o que não é dito, sobre a impossibilidade de dizer e pensar que é retirada de cada indivíduo num regime de exceção. Inicialmente, essa outra história é narrada por meio dos itálicos. Eles sublinham uma atenção que deve ser redobrada ou marcam palavras que aludem a um segundo sentido para aquele mesmo excerto. É assim que Marcelo Maggi aconselha a seu sobrinho, Emilio Renzi, o máximo de prudência, além de um "olhar histórico", sem que se saiba exatamente o porquê:

Debo pedirte, por otro lado, la máxima discreción respecto a mi situación actual. Discreción máxima. Tengo mis sospechas: en eso soy como todo el mundo. De todos modos, ya te digo, actualmente no tengo vida privada. Soy un ex abogado que enseña historia argentina a jóvenes incrédulos, hijos de comerciantes y chacareros de la localidad. Este trabajo es saludable: no hay como estar en contacto con la juventud para aprender a envejecer. Hay que evitar la introspección, les recomiendo a mis jóvenes alumnos, y les enseño lo que he denominado la mirada histórica (Piglia, 2003, p. 20).

Rodolfo Walsh, no romance de não-ficção Operación masacre, reconstitui os fuzilamentos clandestinos perpetrados em junho de 1956 em José León Suárez, supostamente ordenados em reprimenda aos generais Raúl Tanco e Juan J. Valle, que se opunham à destituição de Juan Domingo Perón realizada em 1955. Para a expressa maioria dos civis, massacrados antes que se promulgasse a lei marcial, não se comprovou nem mesmo uma vaga relação com os generais rebelados. No "Obligado apéndice" da primeira edição, Walsh explica:

No hay un solo dato importante en el texto de Operación Masacre que no esté fundado en el testimonio coincidente y superpuesto de tres o cuatro personas, y a veces más. En los 
hechos básicos, he descartado implacablemente toda la información unilateral, por muy sensacional que fuese. Es posible que se hayan deslizado intrascendentes errores de detalle, pero el relato es básicamente exacto y puedo probarlo ante cualquier tribunal civil o militar (Walsh, 2004, p. 207).

Em 1977, um ano após a manutenção da Junta Militar no poder, Walsh, desta vez instigado pela censura da imprensa, pela perseguição de intelectuais e pela execução da filha e de amigos, envia a jornais locais e estrangeiros a "Carta abierta de un escritor a la Junta Militar". Um dia depois, comprovava-se que a denúncia pública e calcada em fatos reais podia receber uma única punição durante aqueles anos: o nome de Walsh passa a integrar a lista de desaparecidos.

Ao contrário desses textos, rigorosamente fundados em testemunhos, Respiración artificial situa-se no campo da ficção, apesar de abrir-se para um sentido ausente no texto. Mostra por estar escondido, sem, com isso, conduzir a uma compreensão integral. A ostranenie e o "concepto de distanciamiento" de Brecht, evocados como necessários no longo diálogo da segunda parte, permitem afastá-lo de um romance de testemunho. Não há testemunhas diretas e a ideia de distância histórica, expressa pelas personagens Marcelo Maggi, Emilio Renzi e Tardewski tem atributos positivos porque relativiza o real e a verdade, diferentemente, por exemplo, do difícil estatuto da distância quando da participação efetiva do Holocausto. José Sazbón (2000) salientaria a ambiguidade da representação histórica no romance, em que os "fatos reais", como versões, não se esquivam de operações de semantização e de articulação figurativas. Edgardo Berg caracterizaria Respiración artificial com uma expressão justa: "testimonio ficcionalizado" (Berg, 2002, p. 77).

Para a literatura de testemunho, o nazismo ou o fascismo não são discursivos. São fatos inegáveis. A ditadura de Respiración artificial não tem rosto, mas é possível ouvi-la ecoando. Combate-se o discurso do Estado com o discurso literário. Piglia não lida com o evento indiscutível, mas com as histórias invisíveis construídas pelo discurso autoritário. Para usar um termo esclarecedor da lingüística, lida com o eixo paradigmático ou vertical, com os diversos modos de percepção do acontecimento.

Podríamos decir que también el Estado narra, que también el Estado construye ficciones, que también el Estado manipula ciertas historias.

Y en un sentido, la literatura construye relatos alternativos, en tensión con ese relato que construye el Estado, ese tipo de historias que el Estado cuenta y dice (Piglia, 2001, p. 2122).

O texto, do mesmo modo, não pode ser enquadrado na categoria de romance histórico: não há circunscrição temporal, tampouco a tentativa de reconstrução do passado, empresa, segundo Juan José Saer (2000), "cuja impossibilidade salta tão imediatamente à vista que não requer mais explicações". A história passada e futura, como tema, não como representação - continua Saer - é convocada para participar como uma das chaves de elucidação nesse "romance-ensaio", escrito numa época em que não se podia argumentar. Como no romance Nadie nada nunca (Saer, 1997), Respiración artificial narra a ditadura senão por meias palavras e insinuações. É precisamente por causa dessa ausência e do irrepresentável que o terror se faz presente. 
As vias indiretas de acesso ao sentido permitiram que o livro escapasse à censura. De acordo com o historiador Tulio Halperin Donghi, os leitores do romance não foram expressivos em número, mas nem por isso deixaram "de crear un clima de opinión" (Balderston, 1987, p. 80), uma vez que entre eles estavam intelectuais e escritores, uma parte, inclusive, no exílio, o que ainda garantiu uma repercussão internacional. Recepção nem sempre positiva, como no caso do próprio ensaio de Halperin Donghi. Este, ao descrever o que chama de uma reavaliação sobre o período rosista e a geração de 1837 , atribui inúmeras restrições a Respiración artificial, pois apresentaria uma visão pouco sólida das relações entre passado e futuro, incluindo temas cujo tratamento mais sistemático seria imprescindível, sugerindo mais do que delineando, postulando mais do que demonstrando. Além disso, o romance é criticado por se arrogar intelectual em virtude dos intertextos e alusões veladas. Características que de fato o perpassam, não de forma negativa, mas antes como elementos renovadores.

$* * *$

Respiración artificial expõe duas grandes partes, cada uma delas com outras subdivisões. A primeira parte, "Si yo mismo fuera el invierno sombrío", narra, em I, o interesse de Emilio Renzi por seu tio Marcelo Maggi, há muito desaparecido. Renzi escreve um romance sobre ele, mesmo sabendo pouco a seu respeito. Logo depois da publicação, Maggi lhe envia uma carta, corrigindo alguns erros e fazendo recomendações. A partir de então, passam a se corresponder. Segundo Renzi, as cartas tinham como assunto principal a pesquisa do tio sobre um agente duplo, Enrique Ossorio: homem de confiança do presidente Juan Manuel de Rosas e seu traidor, possivelmente a serviço de Juan Lavalle. Em II, lê-se o monólogo de Luciano Ossorio, pai da primeira esposa de Maggi e neto de Enrique Ossorio. Em III, a narrativa de um desconhecido - nem Renzi, nem Maggi - investigados nesse trecho. O narrador lê o que lê o censor Arocena, responsável por interceptar e interpretar mensagens cifradas. Como um organograma, cada uma das subpartes de "Si yo mismo fuera el invierno sombrío", designadas por números romanos, subdivide-se ainda em quatro seções dispostas em algarismos arábicos.

A segunda parte do romance, "Descartes", que abriga apenas o episódio IV, traz um longo diálogo entre Renzi e o polonês Vladimir Tardewski, amigo de Maggi. Enquanto aguardam a chegada deste, que nunca ocorrerá, conversam sobre política, literatura, filosofia, ou assuntos extraordinários, como a transferência ao acaso de Tardewski à Argentina quando fugira da Segunda Guerra Mundial; o encerramento da literatura argentina do século XIX com a obra de Borges e o fim da moderna depois da morte de Roberto Arlt; alguns episódios da vida de Marconi e as misteriosas cartas que recebe de uma escritora feia e talentosa; a escuta atenta que Franz Kafka presta a Hitler, quando este era desertor do exército. Diferentemente da primeira parte, cada uma delas ainda subdividida em mais quatro seções, a parte IV de "Descartes" tem apenas três subpartes numeradas.

O romance se encerra, assim, como se alguma coisa tivesse sido deixada de lado: "não há melhor lugar para se guardar um segredo que num romance inacabado", diria uma das personagens de Italo Calvino (1991). A indicação, na estrutura do texto, de que algo está faltando, revela-se, de maneira elusiva, durante toda a narrativa, repleta de intrigas, de histórias de uns e de outros, mas em que se fala demais. Como se os assuntos emendados 
uns nos outros representassem seu contrário, uma espécie de tentativa de ocultar a ordem de silêncio, a fala censurada, as perseguições, o desaparecimento de Maggi. Não é por acaso que um dos assuntos do diálogo entre Renzi e Tardewski seja o antigo professor deste, Wittgenstein, cujo Tractatus Logico-Philosophicus condena ao silêncio uma parte da obra, pois não haveria outro modo frente à resistência oferecida pela linguagem. Apesar disso, o não-dito, porque extrapola os limites da linguagem, embora participe do romance, não constitui a principal forma do silêncio. Em Respiración artificial, não se trata do que foi esquecido ou recalcado, como em Freud, nem do indizível, como Deus, mas do que foi proibido dizer, apesar de flagrante. Na opinião de Daniel Balderston (1987, p. 118), "significado latente": o que o texto oculta e diz através de seu silêncio.

$* * *$

La prolijidad de lo real é o nome do romance da personagem Emilio Renzi sobre seu tio Maggi. O título remete ao que é excessivo e difuso no real. Supõe uma obra extensa, abstrata, talvez pouco meditada, como se reproduzisse uma fala interminável e confusa. "La prolijidad de lo real" é, também, o título de um relato de Piglia (1978) que, com poucas modificações, é repetido nas primeiras páginas de Respiración artificial, quando Renzi se apresenta, escrevendo sobre seu interesse pelo tio e lendo a primeira carta recebida ${ }^{2}$. Afinal, pergunta-se na primeira linha de ambos os textos: a história que será narrada é uma história? Pode ser narrada? De saída, investigação sobre a origem, a necessidade e a possibilidade de narrar, questão que implica, além de uma auto-reflexão, o problema da narração como forma, a interrogação sobre a consciência histórica e a decifração do passado.

Além de algumas palavras e da nova pontuação dos parágrafos, tornados mais curtos para conferir agilidade à narrativa, há três mudanças fundamentais na transposição para o romance: a de uma data, a de uma epígrafe e a do título do livro de Renzi. Numa inversão, o romance que Renzi havia escrito, segundo o artigo de 1978, chamava-se Respiración artificial. O início da história do artigo se daria em 1968. No romance, mudase para 1976, ano do chamado "Proceso de Reorganización Nacional" (1976-1983). A alteração mais significativa está na epígrafe. No relato são dois versos em espanhol, sem nenhuma identificação de autoria. No romance a epígrafe é nova: dois outros versos, dessa vez em inglês, seguidos das iniciais T. S. E. A epígrafe original foi substituída, talvez porque tivesse um sentido notório e, portanto, perigoso perante a censura. Ela faz parte do poema de Jorge Luis Borges, "La noche que en el Sur lo velaron". Nele, descreve-se uma caminhada até um velório, a chegada do visitante que se coloca na vigília, ao lado de outros, e as conversas indiferentes "porque a realidade é maior" (Borges, 2004). Esta última percepção - das palavras banais que se desfiam em vez de uma conversa sobre a morte adquire maior acuidade quando lida como intertexto de Respiración artificial. O confronto do poema com o romance marca, uma vez mais, a atmosfera incerta sob a qual está Marcelo Maggi (e muitos outros), talvez capturado pelos militares, talvez assassinado. Os dois últimos versos do poema de Borges, transcritos a seguir, correspondem à epígrafe do artigo de Piglia. O último coincide com o título do livro de Renzi em Respiración artificial:

(El velorio gasta las caras;

los ojos se nos están muriendo en lo alto como Jesús.) 
¿Y el muerto, el increíble?

Su realidad está bajo las flores diferentes de él

y su mortal hospitalidad nos dará

un recuerdo más para el tiempo

y sentenciosas calles del Sur para merecerlas despacio

y brisa oscura sobre la frente que vuelve

y la noche que de la mayor congoja nos libra:

la prolijidad de lo real.

(Borges, 2004, pp. 88-89)

A Renzi, seu primeiro romance desagrada, a não ser pelo título, La prolijidad de lo real, e pelo efeito, as cartas recebidas do tio. Respiración artificial seria, de acordo com Vera Lúcia Figueiredo, um "segundo texto escrito para corrigir um primeiro, ou melhor, para apresentar outra versão da mesma história" (1994, p. 129). Essa hipótese confirma-se na primeira parte de "Si yo mismo fuera el invierno sombrío", quando Renzi mostra-se narrador em primeira pessoa e assume a responsabilidade pela escolha da epígrafe. Mas logo nas primeiras linhas a autoria é colocada em questão, uma vez que o mais comum é o autor escolher a epígrafe de seu romance, não a personagem. Biografia e ficção, além das categorias de narrador e autor, se embaralham, afinal, Renzi é uma espécie de duplo de Ricardo Piglia: ambos são escritores, têm a mesma idade, nomes que se superpõem, parecem fisicamente ${ }^{3}$.

Na seqüência do romance, a voz de Renzi se enfraquece e chega, mais adiante, a se ocultar momentaneamente. Na segunda subdivisão de "Si yo mismo fuera el invierno sombrío", há um monólogo de Luciano Ossorio, neto de Enrique. Ele pode ser dirigido a Renzi, mas não há nenhuma passagem clara que o ateste. Apesar disso, muitos estudos sobre o romance presumem que houve aí uma visita de Renzi a Luciano Ossorio, fundada, provavelmente, na quarta parte da primeira subdivisão, imediatamente anterior à fala de Luciano Ossorio, quando Maggi escreve a Renzi:

Algunos contratiempos inesperados me han obligado a cambiar mis planes. De todos modos me gustaría que en algún momento pudieras venir a verme. Ya te avisaré el modo y la forma. ¿Me harías entretanto el favor de visitarlo a don Luciano Ossorio y darle saludos míos? No sé si podré alcanzar a escribirle. Te he dicho más de una vez, de un modo sin duda demasiado enfático o cómico, que la historia es la que para mí arma estas tramas. No debemos desconfiar, por otro lado, de la resistencia de lo real o de su opacidad. La paloma que siente la resistencia del aire, dice mi amigo Tardewski citando a Kant: La paloma que siente la resistencia del aire piensa que podría volar mejor en el vacío (Piglia, 2003, pp. 34-35).

Quando a fala de Luciano Ossorio tem início - "'Puede llarmarme senador', dijo el senador" (Piglia, 2003, p. 45) - esse que se restringe a reproduzir o falado, sem transmitir as saudações de Maggi, apenas introduzindo as aspas, parece ser Renzi. Contudo, o leitor, alertado por Maggi, de um lado sobre as tramas da história e, de outro, sobre a resistência 
ou opacidade do real, às vezes mais necessária que fatídica, pode escolher entre os dois caminhos. Preferindo a resistência do ar que permite o vôo suave da pomba, haveria um diálogo entre Renzi e Luciano Ossorio. No entanto, também é possível desconfiar da conspiração da história à que primeiro aludiu Maggi, das armadilhas que prega.

Luciano Ossorio conta sua história. É um ex-senador, vive enclausurado, pois é paralítico há mais de cinqüenta anos, quando recebeu um tiro durante um comício. Recebe cartas do censor Arocena, escritas com o fim de aterrorizá-lo, além de outras que não lhe foram destinadas e por isso têm de ser decifradas. Seu principal temor, por causa da velhice, é o de "perder el uso de la palabra" (Piglia, 2003, p. 49), sua única posse e atividade. O monólogo, em alguns trechos, aproxima-se do delírio. Talvez o ex-senador já tenha encontrado o que teme, o nexo de suas palavras não é confiável: "'Tengo esa misión, entre otras', dijo. 'Esa misión. ¿Ve? Sobre el mueble. ¿Por qué debo ser yo? No necesariamente me están dirigidas. Llegan hasta mí [las cartas]. ¿Las sueño? Nunca he podido distinguir el sueño de la vigilia. Están ahí, sin embargo'"(Piglia, 2003, p. 49).

Seu pai morrera num duelo em defesa da honra de seu avô, Enrique Ossorio. Sua fortuna, herdada do ouro que o avô encontrou na Califórnia durante o exílio, não pode ser transmitida aos filhos enquanto a morte não o ceifar. Por isso, descreve-se como o responsável por interromper uma cadeia natural: está muito velho, mas não morre. Orgulhase do avô, que considera um herói. Tem especial apreço pelo ex-genro, Maggi, e transmite a seu ouvinte, que irá encontrá-lo, recomendações para que cuide de si e também das cartas que envia, pois podem ser interceptadas, como talvez o sejam, por Arocena, na terceira subdivisão do primeiro conjunto do romance.

A dúvida se coloca, pois algumas cartas são datadas de 1850, outras, geralmente sem data, provavelmente remetem aos acontecimentos da década de 1970. Nesse trecho, também parece estar recolhido parte do diário de Enrique Ossorio. O eixo temporal é ambíguo e sugere um paralelo entre dois períodos: o censor pode tanto pertencer à época da ditadura de Rosas (mantida entre os anos de 1837 e 1852), como à do regime autoritário contemporâneo à publicação de Respiración artificial. A confusão acentua-se ainda mais porque Enrique Ossorio, durante o desterro nos Estados Unidos, escrevera um romance sobre o futuro, mais precisamente sobre 1979. Seriam, dessa maneira, cartas visionárias escritas no passado? O romance seria uma espécie de texto utópico às avessas, em que no passado, quando fora escrito, previra-se um futuro de manutenção das ações autoritárias do Estado do século XIX? Afinal, seria possível que Enrique Ossorio previsse a existência de Maggi e Renzi, além de um sistema de espionagem? As personagens existem ou, na verdade, são ficções?

Reabertura do passado para revisitar suas potencialidades. O presente, reinvestido de um horizonte histórico deslocado, transforma a distância temporal em geração de sentidos que distorcem a explicação histórica e aumentam a força ética e política do que poderia ter sido. A interseção com o passado não anula a distância que o separa do presente, fazendo-o reviver. Estabelece, antes, contradições e diferenças, levando o leitor a se posicionar num entre-lugar, onde não é possível dominar nem os fatos de um, nem os de outro. Instabilidade interpretativa, como a que enfrenta Arocena. Assim como o passado, qualquer conhecimento pode ser recontado de inúmeras formas, variando de acordo com os diferentes pontos de vista e interesses: 
Miró la frase. Estaba ahí, escrita en el papel. Raquel llega a Ezeiza el 10, vuelo 22.03. ¿Y si no fuera así? ¿Quién podía confiar? Raquel: anagrama de Aquel. Escribió Aquel en una ficha. La dejó aparte. Ezeiza: e/e/i/a. Doble z. ¿Una aliteración? Estaban las cifras: 22.0310. La $e$ se repite seis veces en toda la frase. La $a$ se repite cuatro veces en toda la frase. Hay una $o$ y una $i$. Cada palabra podía ser un mensaje. Cada letra. ¿Quién llega? ¿Quién está por llegar? Las cifras: 2.20.31.0. E/e/a/i/u/o. Doble z. Raquel: un anagrama. ¿Quién llega? ¿Quién está por llegar? A mí, pensó Arocena, no me van a engañar (Piglia, 2003, p. 103).

Arocena estende ao leitor os artifícios das correspondências de sentido entre os mais diversos textos. Obsessão compartilhada com as outras personagens de Respiración artificial, todas diante da necessidade e do perigo do desvendamento.

$$
\text { *** }
$$

— Precisamente - dijo Albert - El jardín de senderos que se bifurcan es una enorme adivinanza, o parábola, cuyo tema es el tiempo; esa causa recóndita le prohíbe la mención de su nombre. Omitir siempre una palabra, recurrir a metáforas ineptas y a perífrasis evidentes, es quizá el modo más enfático de indicarla (Borges, 2004, p. 478-479) ${ }^{4}$.

Mesma estratégia narrativa adotada em Respiración artificial, omitir sempre, recorrer a metáforas e perífrases, mas além dos tempos do conto de Borges, as tramas superpostas. Em ambos, as personagens são movediças, conhece-se apenas uma parte de suas histórias e do que dizem. Por vezes nem é possível situá-las num século ou noutro.

No romance de Piglia, as divisões e subpartes permitem mudar de assunto, de tempo, de lugar. Salta-se de uma história a outra. Em cada uma, sobressai a voz de uma personagem que se mostra parcialmente, com suas idiossincrasias, suas amizades, seus interesses. No terceiro texto do primeiro conjunto, essa explosão de histórias sem vínculos atinge seu ápice, quando o leitor acompanha o trabalho de Arocena ao decifrar correspondências suspeitas. Sucedem-se cartas de Enrique Ossorio sem destinatários, misturadas com a de muitos outros, desconhecidos do leitor, que interpelam a outros que até então não faziam parte do romance. Não há um núcleo que unifique as histórias e essa falta de centro leva à sensação de uma desarmonia formal, de um texto aparentemente esboçado e não terminado. Para Balderston (1987), o romance se constitui por meio de contradições e omissões de nexos importantes para o argumento.

A ficção convidaria a compreender o que é da ordem do variável e do construído. Gesto libertário e angustiante, pois muitas expectativas não são satisfeitas, muitas perguntas permanecem sem resposta. Soma-se a isso a pequena confiança depositada nos narradores, o que faz com que a responsabilidade do sentido recaia sobre o leitor. As incertezas o tornam um detetive, fazendo-o conectar informações por meio de hipóteses e se reposicionar a cada novo elemento, num desvestir constante das conexões encontradas. As soluções parciais, contudo, não são inteiramente descartadas. Permanecem em suspense, à espera que na junção com outras histórias voltem a ganhar relevo. Há, pois, um excesso de sentidos disponíveis. A suspeita irradia para todas as direções e propicia o desenvolvimento de um delírio interpretativo. 
Cada uma das personagens é dúbia: são testemunhas do horror e suspeitas porque vigiadas pela arbitrariedade estatal. Apesar de o leitor ser levado a atuar como detetive, o crime não foi estabelecido em nenhum momento. Há uma investigação sem causa delimitada. Por esse não-motivo, as questões do leitor-detetive são "quem é quem?" e "o que dizem?", antes de "quem fez?" ou "quem é o culpado?". Mesmo porque não são personagens de ação, mas leitores, pares daqueles que lêem Respiración artificial. O romance de Renzi, por exemplo, foi escrito com "el tono de Las palmeras salvajes: usando los tonos que adquiere Faulkner traducido por Borges con lo cual, sin querer, el relato sonaba a una versión más o menos paródica de Onetti" (Piglia, 2003, pp. 17-18). A epígrafe escolhida para o romance não resulta apenas da leitura de Eliot, mas do verso de uma foto de família onde o texto fora transcrito por Maggi. Sua origem é, assim, compartilhada por três identidades: a do escritor, Piglia, e a de suas personagens, Renzi e Maggi. Estes não são os únicos leitores, responsáveis por diversas apropriações e referências a outras obras. Maggi revela-se leitor nas cartas que escreve, pois coleciona e organiza os papéis deixados por Enrique Ossorio. Luciano Ossorio, por sua vez, situa-se como um continuador do poeta Leopoldo Lugones e da moda iniciada por este de fazer discursos, com sua consequente desestima depois de tantos pronunciamentos patrióticos e comemorativos. Diz-se, ademais, leitor de mensagens alheias, além de imaginar a escrita do avô Enrique nos dias finais do exílio. Em seguida, outro leitor, o censor Arocena. No segundo conjunto do romance, o diálogo entre dois leitores: Tardewski - citando Wittgenstein, Shakespeare, Joyce, Conrad, Pascal, Platão, Kafka, Hitler e outros - e Renzi - leitor de Tinianov, Gombrowicz, José Hernández, Borges, Arlt, Brecht. Todos eles "debruçam-se sobre textos de várias naturezas - cartas, jornais, literatura, filosofia" (Figueiredo, 1994, p. 127) - tentando decifrar a mensagem secreta dessas informações que circulam de forma obscura. Configuram, nas palavras de Edgardo Berg, uma "cadena de lectores y buscadores de sentidos" (2002, p. 62). Suas experiências são teóricas, seus conhecimentos, mediados por textos e fragmentos de textos e, portanto, por outros. A fala das personagens é conhecida permanentemente através do discurso de outros, da opinião de outros.

$$
* * *
$$

Em três contos publicados antes de Respiración artificial, a tônica do enigma dependia de um texto escrito. Em "Las Actas del juicio", de 1964, transcreve-se o depoimento de um caudilho, Robustiano Vega, responsável pelo assassinato do general Justo José de Urquiza. A decisão dos subordinados de Urquiza de abandoná-lo fora tomada durante uma chuva torrencial, quando não se podia respirar. Vega justifica sua conduta dizendo que o general já estava morto: "— Fue por todo eso que yo lo hice. Pero ya había sucedido antes, la noche aquella en los Bajos de Toledo, mientras la lluvia no nos dejaba respirar ocupando todo el aire" (Piglia, 1998, p. 166).

Em "Mata-Hari 55", de 1966, transcrevem-se duas fitas cassete, cujo assunto gira em torno das ações de uma espiã. As iniciais de Ricardo Piglia emolduram um texto em itálico, disposto à direita, como uma epígrafe, antecedendo as confissões gravadas no bar Ramos:

La mayor incomodidad de esta historia es ser cierta. Se equivocan los que piensan que es más fácil contar hechos verídicos que inventar una anécdota, sus relaciones y sus leyes. La 
realidad, es sabido, tiene una lógica esquiva; una lógica que parece, a ratos, imposible de narrar. Frente al riesgo de violentarla con la ficción, he preferido transcribir casi sin cambios el material grabado por mí en sucesivas entrevistas. La lealtad del Grundig W2A portátil sirve como testigo de la verdad de este relato que me fue referido, por primera vez, entre el atardecer y la medianoche de un día de verano, en el bar Ramos de Corrientes y Montevideo (Piglia, 1998, p. 148).

Num outro conto, "La loca y el relato del crimen", de 1975, narra-se o assassinato da prostituta Larry. O crime teve como única testemunha uma mendiga louca, chamada Echevarne Angélica Inés. O motivo do crime não é esclarecido em momento algum. Larry vivia com Antúnez, acusado injustamente por sua morte. Emilio Renzi, nesse conto, jornalista de $E l$ Mundo, realiza uma investigação, descobre que Antúnez é inocente e tenta reverter sua prisão ${ }^{5}$. Depois que comprova a sua inocência, leva o resultado das investigações para Luna, chefe do jornal. Este se recusa a publicar a descoberta porque não quer contrariar a polícia. O primeiro e o último parágrafo do conto são os mesmos, com exceção de um aposto - "empezó a escribir Renzi".

Jornalista-detetive desacreditado, ele se converte num escritor que tenta fazer de suas palavras uma saída para a injustiça. Sua experiência, como paródia da condição do intelectual, pode ser unicamente livresca. Em retrospectiva, o conto fora narrado por Renzi, escrevendo sobre si em terceira pessoa. Mesma atitude distanciada das personagens de Respiración artificial, com a diferença de que no romance é a fala, não a escrita, que adquire relevância. Abandono do suporte oficial que prova, registrando para sempre. Escolha do veículo fluído, cuja materialidade se perde no instante seguinte à pronúncia. Valorização explorada nos romances seguintes, La ciudad ausente e Plata quemada, mas vigorosamente experimentada em Respiración artificial, precisamente no diálogo entre Renzi e Tardewski: "Hay que pensar en contra de sí mismo y vivir en tercera persona. Eso dice Renzi que le decía en sus cartas el profesor Maggi. Brindemos entonces por él, le digo. Por el profesor Marcelo Maggi, que aprendió a vivir en contra de sí mismo. Salud, dice Renzi. Salud, le digo" (Piglia, 2003, p. 113).

$$
\text { *** }
$$

As personagens, suspeitas em potencial, não têm opiniões diretas. A verdade está sempre na voz do outro. Jamais se lê uma carta de Maggi a Renzi. As frases são entrecortadas por apostos explicativos - "me escribía Maggi" - que denotam um relato híbrido de Renzi explicando o que Maggi escrevera. No fragmento transcrito a seguir, Renzi enuncia as razões da escrita de Maggi, apesar deste ter informado pouco antes que dispensava justificativas:

A mis años aprendí que no necesito esconder nada; aprendí, quiero decir, me escribía Maggi, lo que ya sabía: que no necesito justificaciones. No te escribo, entonces, me escribía Maggi, porque busque rescatar algo en medio de esta desolación, te escribo porque los años me han fijado los recuerdos como un sarro y el pasado se ha convertido para mí en un viejo tullido (Piglia, 2003, p. 26). 
As histórias de Luciano Ossorio recebem tratamento semelhante. Em seu monólogo, elas não são transcritas diretamente. Alguém narra o que Luciano disse e, quando as palavras parecem não ter mediação, inevitavelmente recebem aspas. Esse sinal gráfico indica a presença de alguém delimitando com alguma ênfase que aquelas palavras não são suas: "El senador dijo después que eso era todo lo que él podía hacer. 'Eso', dijo el senador, 'es todo lo que yo puedo hacer. Aislado, solo, insomne, es todo lo que puedo hacer. Dictar, desde aquí, palabras de alivio, pasearme, de un lado a otro, pensar las cartas, las respuestas, todo ese dolor'"(Piglia, 2003, p. 66).

Trata-se de uma transmissão indireta que talvez modifique o primeiro texto ao passar por essa espécie de tradutor de palavras, que, no diálogo da segunda parte, ora é Emilio Renzi, ora Tardewski. Embora a segunda metade do romance seja mais homogênea do que a primeira, pois não há crônicas de família, cartas, documentos, monólogos, pedaços de ficção - há apenas um diálogo - do ponto de vista narrativo, não é menos complicada. A primeira subdivisão é narrada por Tardewski, reproduzindo a conversa com Renzi e transcrevendo sua fala e a de seu interlocutor, como se fizesse questão de reafirmar palavras ditas de um modo e não de outro. No excerto seguinte, podem-se observar cinco expressões "le digo" que destacam sua insistência:

¿Verlo [a Maggi]? ¿Por qué no? Si le ha dicho que viniera hoy, le digo [a Renzi], es porque hoy es el día que ha elegido, sin duda, para regresar. Vamos a esperarlo, le digo. Si ha querido irse, también ahora puede querer volver, le digo. Podemos esperarlo toda la noche. Estoy seguro de que hoy él va a volver. Tenemos tiempo, le digo, recién a las seis de la mañana sale el tren para Buenos Aires. Si él no regresa podrá entonces usted tomar ese tren. Nos quedaremos juntos, le digo, si le parece, hasta la madrugada, esperando que llegue el profesor (Piglia, 2003, p. 117).

Nas duas últimas subdivisões de "Descartes", Renzi narra, embora Tardewski seja o principal enunciador, marcando seus "a veces", "quizás", "tal vez"; os acasos, em suma, determinantes para o seu destino:

A veces, dijo, se le daba por pensar qué hubiera sido de su vida de haberse quedado en Europa o de haber regresado al final de la guerra. Quizás hubiese muerto en un campo de concentración o quizás, dijo, de haber seguido en Londres sin la ocurrencia de irse a veranear a Varsovia justo en agosto de 1939 y en caso de haber sobrevivido a los bombardeos, tal vez, en ese caso, dijo, hubiera terminado mi doctorado y hoy sería profesor de filosofía en alguna universidad inglesa o norteamericana. Más de una vez, dijo, había reflexionado sobre su vida, sobre el azar que había tejido su destino (Piglia, 2003, p. 155).

A estratégia que burla a censura em Respiración artificial é dizer o que outro diz, esse outro dizendo sobre outro que diz sobre outro - num disfarce em espiral das opiniões e pontos de vista. Com falas aparentemente enfraquecidas, o romance sugere uma união de vozes que, sem identificação clara, podem dividir a responsabilidade do que está sendo contado, podem falar contra, pois nenhuma delas será delatada. Não é possível formular uma denúncia ou apontar um acusado nesse jogo de personagens cruzadas, nesse movimento geral de fuga constante da autoria. 
Há uma oposição entre os títulos dos conjuntos do romance. No primeiro, "Si yo mismo fuera el invierno sombrío", baseado num quadro apócrifo de Franz Hals, evocam-se sombras, a falta de clareza, a melancólica escrita de Renzi, paralisada pelo "frio". O segundo, "Descartes" aponta para uma conclusão, quiçá "la verdad de la historia" mencionada como conhecida na dedicatória de Respiración artificial.

Tanto o romance de Piglia quanto o texto mais famoso de Descartes, Discurso do Método, propõem o desafio da dúvida, contra a facilidade de uma resposta única. Escreve Descartes:

Fui instruído nas letras desde a infância, e por me haver convencido de que, por intermédio delas, poder-se-ia adquirir um conhecimento claro e seguro de tudo o que é útil à vida, sentia extraordinário desejo de aprendê-las. Porém, assim que terminei esses estudos, ao cabo do qual se costuma ser recebido na classe dos eruditos, mudei totalmente de opinião. Pois me encontrava embaraçado com tantas dúvidas e erros que me parecia não haver conseguido outro proveito, procurando instruir-me, senão o de ter descoberto cada vez mais a minha ignorância (Descartes, 1999, p. 37).

Diante da "pluralidade das vozes" encontrada por Descartes, faz-se necessária uma concentração espiritual, num quarto fechado, onde, sozinho, tenta uma resposta. Tal gesto sintetiza o de grande parte das personagens do romance de Piglia: Enrique Ossorio num hotel nos Estados Unidos; Luciano Ossorio, paralítico, em seu quarto; Maggi, cuja primeira carta enviada a Renzi informava que quase não saía. Sobretudo Renzi e Tardewski, na cidade de nome bastante sugestivo, Concordia, fechados numa casa durante toda uma noite, enquanto conjeturam o paradeiro de Maggi.

Sabe-se que os fatos são duvidosos, por isso Descartes elaborou preceitos estritos, com a finalidade de encontrar um sentido "firme e inalterável", o entendimento claro e distinto das coisas, preocupação diretamente relacionada com a utilidade verdadeira dos acontecimentos, com "a real utilidade da respiração", a de "levar bastante ar fresco aos pulmões"(Descartes, 1999, p. 79). Até o momento final de Respiración artificial, as dúvidas se somavam ininterruptamente, manifestando uma debilidade diante do que escapava a tantas histórias superpostas. Na última cena, quando o texto parece prestes a comunicar o pouco que já tivesse descoberto - único remédio contra a morte e a falta de experiências, como em Descartes - Renzi abre uma das pastas entregues por Tardewski. São os papéis deixados por Maggi. Tudo parece clarear, como o dia:

Tardewski se ha arrimado a la ventana. Está de cara a la débil luz que agrisa el aire de la noche. Está de espaldas a mí. Mira hacia fuera y dice que ya ha empezado a clarear, que pronto va a amanecer.

Está clareando, dice. Pronto va a amanecer.

Yo abro una de las carpetas.

Al que encuentre mi cadáver (Piglia, 2003, p. 217-218) ${ }^{6}$ 
Dedicatória mórbida na primeira frase de Enrique Ossorio. Em seguida, lê-se a última carta escrita por ele, indicando o lugar onde está guardada uma segunda - não reproduzida no romance - destinada a Juan Bautista Alberdi, na qual se explica, aí sim, o motivo da decisão pelo suicídio. Perguntamo-nos, com Renzi: Maggi quis dizer algo por meio dos papéis deixados como herança? Ele não pôde vir a seu encontro, pois foi capturado? Diz sobre si como dizendo em terceira pessoa, ou seja, suicidou-se como Enrique Ossorio? Falsa percepção de que tudo se tornaria claro. Há ainda um segundo texto a ser encontrado; outra história. A incerteza e a dúvida permanecem. O romance termina na iminência do sentido, antes que o dia amanheça por completo. A luz é fraca e apenas acinzenta o ar que respiramos. 


\section{Referências bibliográficas}

BERG, Edgardo. Poéticas en suspenso, migraciones narrativas en Ricardo Piglia, Andrés Rivera y Juan José Saer. Buenos Aires: Biblos, 2002.

BORGES, Jorge Luis. Obras completas, vol. I. 15ª ed. Buenos Aires: Emecé, 2004. BRECHT, Bertold. Grand-peur et misère du III ${ }^{\mathbf{e}}$ Reich. Texte français de Maurice Regnaut et André Steiger. Paris: L'Arche, 1971.

CALVINO, Italo. O castelo dos destinos cruzados. Tradução Ivo Barroso. São Paulo:

Companhia das Letras, 1991.

DESCARTES, René. Discurso do método. Tradução Enrico Corvisieri. São Paulo: Nova Cultural, 1999.

FIGUEIREDO, Vera Lúcia. "Ricardo Piglia: as margens da história", Da profecia ao labirinto. Rio de Janeiro: UERJ, 1994.

BALDERSTON, Daniel \& otros. Ficción y política, la narrativa argentina durante el proceso militar. Buenos Aires, Madrid: Alianza, University of Minnesota, Institute for the Study of Ideologies \& Literature, 1987.

PIGLIA, Ricardo. "La prolijidad de lo real", Punto de vista, año I, nº 3, 1978, pp. 26-28.

Crítica y ficción. Buenos Aires: Planeta, 2000.

Cuentos morales, $2^{\mathrm{a}}$ ed. Buenos Aires: Planeta, 1998.

Respiración artificial, $2^{\mathrm{a}}$ ed. Buenos Aires: Seix Barral, 2003.

Tres propuestas para el próximo milenio (y cinco dificultades). Buenos Aires:

Fondo de Cultura Económica, 2001.

SAER, Juan José. "História e romance, política e polícia", Folha de S. Paulo, 24/12/2000, p. 22.

Letras, 1997.

Ninguém, nada, nunca. Tradução Bernardo Carvalho. São Paulo: Companhia das

SAZBÓN, José. "La reflexión literaria". In: FORNET, Jorge (comp.). Ricardo Piglia.

Bogotá: Fondo Editorial Casa de las Américas, Instituto Caro y Cuervo, 2000, pp. 119-139.

WALSH, Rodolfo. Operación masacre. 27ª ed. Buenos Aires: De la Flor, 2004.

\footnotetext{
${ }^{1}$ Tradução do francês e grifo meus.

${ }^{2}$ Mais precisamente, o texto de Piglia transposto para o romance vai da primeira frase do romance, "¿Hay una historia?", até a reelaboração de uma das frases do Ulisses de Joyce: "La historia es el único lugar donde consigo aliviarme de esta pesadilla de la que trato de despertar" (Piglia, 2003, p. 21).

${ }^{3}$ Alguns traços físicos, como a descrição que Renzi faz de si: "soy más bien bajo, pelo crespo, uso anteojos" (Piglia, 2003, p. 92), pertencem igualmente a Piglia, cuja fotografia, inclusive, ilustra orelhas de algumas edições do romance.

${ }^{4}$ Notar, no mesmo conto, a semelhança das frases sobre Madden, p. 472, "Irlándes a las órdenes de Inglaterra (...)", e de Maggi sobre si mesmo, em carta a Renzi: "Caballero irlandés al servicio de la reina." (Piglia, 2003, p. 20).

Como Renzi, Echevarne Angélica Inés também reaparece em Respiración artificial, desta vez, como uma vidente ou uma mulher alucinada pelo medo, autora de uma carta interceptada por Arocena, em que relata suas visões, provavelmente de torturados.

${ }^{6} \mathrm{O}$ recuo pertence ao original.
} 